\title{
Invaded by Cancer, and the Patient is Me
}

Susan M. Smith, BS, PharmD, BCPS

Wingate University School of Pharmacy

\begin{abstract}
A cancer diagnosis is life-altering. Each patient situation is unique, including response to the news, approach to available treatment options, and insight into every aspect of life. As a pharmacist, the author shares personal insights into living with a cancer diagnosis, her new role as a patient, her perspective as a pharmacist, processing the reactions of those surrounding her, and what she's learning about herself through all of this.
\end{abstract}

Keywords: multiple myeloma, cancer, pharmacist perspective, patient role, self-reflection, support group

\section{Introduction}

On Tuesday, January 29, 2019, I was diagnosed with multiple myeloma (MM).

On the evening before, I had made plans for the day that differed from my usual routine: I was going to wake up early to do some work from home, carpool to campus with my collegeage daughter Melanie, enjoy a manicure together in the afternoon, and then join my husband Rob for dinner. I woke up early as planned, but what was not part of the day's plan was to find an email message from the health system's patient portal informing me of a new test result. Confused to receive such a message electronically - since I had a doctor appointment on Wednesday to discuss recent test results - my eyes ran wildly over the 3-page pathology report and crash landed on the line "final diagnosis: lambda restricted multiple myeloma". The shock I felt at reading this report was indescribable - I had no words, no tears, no nothing. Two hours later, when Rob's alarm went off, I hit him with the news. We decided not to tell anyone else right away, including our children. We thought it best to first meet with the doctor so he could answer our questions and let us know what the next steps would entail. (I suppose, too, we hoped the doctor would inform us that we interpreted the report incorrectly, that I did not have MM.) The rest of what was to be a very long day got back on schedule. The day itself was bright and sunny, my mood was anything but.

The words that follow comprise a reflection of insights involving my disease, becoming a patient, being a pharmacist, relating to people around me, and learning about myself through it all.

Corresponding author: Susan M. Smith, BS, PharmD, BCPS Assistant Professor, Pharmacy Wingate University School of Pharmacy; Wingate, NC Email: su.smith@wingate.edu

\section{Insights into my disease}

To help the reader better understand why we were extremely shocked to learn I had multiple myeloma, I will back up to explain what had happened over the previous 59 days. On December 2, 2018, my primary care physician (PCP) requested I come in to discuss an elevated total protein result noted on a comprehensive metabolic panel obtained during my annual physical exam 12 days earlier. I was completely asymptomatic, and to be honest, felt my PCP was merely chasing down an abnormal lab result for academic purposes. I did, however, schedule the first of what was to be many follow-up appointments over the next eight weeks to pursue lab testing (serum protein electrophoresis, immunofixation electrophoresis, flow cytometry) and undergo procedures (skeletal survey, PET-CT, bone marrow biopsy). My lab results showed an elevated IgG level and an elevated monoclonal protein (M-spike), both of which could be present in monoclonal gammopathy of unknown significance (MGUS), smoldering myeloma, or multiple myeloma. MGUS is a noncancerous condition with a lower risk of developing into active $\mathrm{MM}$, while smoldering myeloma is a pre-cancerous condition with a higher risk of leading to active MM. The results of my skeletal survey and PET-CT were negative; in fact, the PET-CT report stated, "no hypermetabolic malignancy or lytic lesions identified". I received these results on January $17^{\text {th }}$ and was hopeful the results of the bone marrow biopsy performed January $15^{\text {th }}$ would be either MGUS or smoldering myeloma.

The classic symptoms of $\mathrm{MM}$ include hypercalcemia, renal insufficiency, anemia, and bone lesions. Together, they make up the acronym 'CRAB'. The presence of these symptoms indicates end-organ damage associated with $\mathrm{MM}$. I did not have any CRAB symptoms. In 2014, the International Myeloma Working Group expanded the definition of active multiple myeloma to include three myeloma-defining events (MDEs): free light chain ratio $\geq 100$, a focal lesion on magnetic resonance imaging, or plasma cells on bone marrow biopsy $\geq 60 \%$. ${ }^{1}$ Plasma cells in the range of $10-60 \%$ would indicate smoldering myeloma, while less than $10 \%$ would indicate MGUS. Unfortunately, my MDE was a bone marrow biopsy result that 
showed plasma cells in the $60-70 \%$ range. At the risk of repeating myself, I can't overstate how shocked we were by the bone marrow biopsy results given my total lack of symptoms, the negative PET-CT, and my personal demographics. MM is more common in black men in their late 60's. I am a white female in my early 50's. But cancer doesn't always play by the rules, so 18 days after receiving my MM diagnosis, I began treatment for cycle 1.

I now know much more about multiple myeloma than I ever really wanted to know. Having said that, I'm not exaggerating when I say that my husband Rob, who is not a healthcare professional, knows more about MM than me. He found resources from the International Myeloma Foundation, ${ }^{2}$ the Multiple Myeloma Research Foundation, ${ }^{3}$ and even signed up for a webinar that discussed the findings from the 2018 American Society of Hematology conference. He has devoured this information, reading as much as he can to better understand this disease. On the other hand, my approach to learning about this cancer could best be described as the proverbial ostrich head in the sand. For the first few weeks into my treatment, I couldn't search the internet on my own (probably not a bad thing), but neither could I read any of the materials they gave us-or talk to anyone else about their journey with MM. It used to be that if anyone I knew had just received a new medical diagnosis of any kind, I would have been all over the computer looking up information. I just couldn't do it for myself. This aversion I had to seeking information has been very difficult for me to understand. I attributed it to being in denial, but I think it could have stemmed from not wanting to see statistics about survival, remission, and the dreaded " $R$ " word - relapse. It took me a month or so, but once I had time to process everything, recognize that the benefit of gaining knowledge was so much greater than any perceived risk, and take another step closer towards acceptance of this disease, I began to read the patient education material, seek out a support group, and reach out to people who had been through what I'm going through. It's still very hard to read some of the material when the first line starts out by reminding me that there is no cure for MM. Other patient information is a little less dire and says that it's rarely curable (implying that it can be cured), or that only a few people have been cured. Well, maybe I can be one of those few people!

\section{Insights as a patient}

I decided from the very beginning that I would go into this as a patient, not as a pharmacist, but it's impossible to take the pharmacist out of who I am! There are aspects to my current therapy and upcoming stem cell rescue that I just know. I cannot simply 'un-know' these things. Most of the time my knowledge has been helpful, sometimes, not so much. If I've heard it once, I've heard it a thousand times: "The good thing is, you're a pharmacist. The bad thing is, you're a pharmacist!" Despite my reluctance to read about the disease itself, I have been more willing to read about the medications that are part of my induction therapy. Maybe it's an inner sense of duty I have as a pharmacist that I should know all that I can about my medications, or just that I want to be a 'good' patient. Either way, I diligently read all the medication-specific booklets and education material I received at the outset of therapy.

As I write this, I have been through five cycles (21-days each) of induction therapy. I was started on VRd (or RVD) standard therapy with bortezomib (Velcade), lenalidomide (Revlimid), and dexamethasone. I almost felt a little guilty that my regimen consisted of two oral medications and subcutaneous bortezomib; it almost seemed 'too easy', especially compared to patients who require time-consuming infusions. (In the hopefully very distant future, I may end up needing an all-day infusion, so I decided to let go of the guilt!) In addition to these three medications, I started valacyclovir, aspirin, and pantoprazole for varicella zoster virus reactivation prevention, deep vein thrombosis (DVT) prevention, and as gastrointestinal protection, respectively. My husband bought me a very colorful morning/evening pillbox, and we took that, and all of my medications, including calcium, vitamin $\mathrm{D}$, and a multivitamin (MVI), to my pharmacist education appointment. I almost didn't take the bottle of MVI, thinking it would be no big deal to continue taking, but was glad I did when the pharmacist set it aside and recommended I avoid any added vitamin C while taking bortezomib. It was a good thing she didn't make assumptions about what I might know about my chemotherapy.

I have been very fortunate in that I have not had any major adverse effects. A few minor side effects did crop up throughout the treatment cycles, but they were all self-limiting. If I was asked at the outset which medication I thought would have been the most challenging, I would have picked either bortezomib or lenalidomide, mostly because they are the official chemotherapy medications of my regimen. But I must say, I raised a 'hallelujah' when I took my last weekly dose of dexamethasone $40 \mathrm{mg}$ of cycle 5! It was a little worrisome at first trying to distinguish steroid-induced heart palpitations from a lenalidomide-induced myocardial infarction, but I soon became accustomed to the sound of my heartbeat in my ears every Friday and Saturday after I took my dose Friday morning. Dexamethasone-induced insomnia was also problematic. I usually fell asleep fairly quickly, but then woke up in the middle of the night and couldn't fall back asleep, despite taking $50 \mathrm{mg}$ of diphenhydramine to counteract the insomnia. There are only so many things you can come up with to think about while lying in bed for two hours! I did have more energy Friday and Saturday which helped overcome the sleep disruptions, but it came at a price by the time Sunday afternoon rolled around. The steroid 'crash' hit me hard some days; for someone who likes to be doing something while sitting down (like reading, sewing, or crocheting), the struggle to find the desire to do more than just sit there and look out the window was real.

I am astounded at the resources available to patients. I knew many of these services existed, but to actually receive a tangible 
benefit from so many people and organizations has really been a huge blessing. I am doing my best to incorporate as many of them as I can, but at times even that can be quite overwhelming! So far, I have taken advantage of my access to nurse navigators, my insurance case manager, counseling sessions, patient aid grants, nutrition counseling, free wigs and scarves, exercise classes, support groups, and survivor peers. And there are still more resources to access!

I had never received counseling before, but I'm very glad I took advantage of this benefit. Free counseling is available to me and to everyone in my immediate family. I made one request of my family - I wanted them to attend at least two sessions. After that, they could decide, along with the counselor, whether they should continue or could stop. We each have a different counselor, and we are all still attending sessions. Sometimes we share a little part of our meetings with each other. It's fascinating to learn how varied the issues are that everyone is working through. Taking advantage of this resource has been one of the best things we've ever done as a family. The tension and stress each of us feels is drastically reduced since we all have someone - that none of us knows - who can help us work through our feelings.

One of the hardest things I have gone through as a patient is the waiting process. Waiting for lab results. Waiting for appointments. Waiting for treatment to start. Waiting for treatment to end. Waiting for the next phase to start. Waiting for the next phase to end. Waiting to get back to normal. One thing I have learned is that the waiting will likely never end. Once I received my diagnosis and began treatment, I settled into a somewhat comfortable routine with the 21-day cycles. After the second cycle, they decided to repeat my M-spike, 'just to see where you're at'. I was told to expect the result in five days. Twelve days after the blood draw, I finally got a call with the result. The days spent waiting on that result were some of the most trying I had experienced, despite having a counseling session that week to talk through ways to combat anxiety! Even before the result came back, I decided I needed to get a grip - I didn't want to live like that. Especially since there will be many more results to wait on in the future that will carry a much higher significance than 'seeing where I'm at'. For instance, I'll be waiting to hopefully hear the words 'you're in remission!' ( $\mathrm{I}$ 'm not even going to talk about the bad ' $\mathrm{R}$ ' word - insert grimacing face emoji here). I have many tools to keep the anxiety at bay so that I can remain calm and be at peace during the waiting. But it's still so hard!

\section{Insights as a pharmacist}

It was definitely self-imposed pressure, but I can honestly say that I have not missed a single dose of medication throughout these five cycles. (I mean, how bad would that be if I was not adherent with my regimen?!). Overall, my regimen was not that complicated: dexamethasone weekly, lenalidomide daily for 14 days and then rest for seven days, and bortezomib at the clinic on days $1,4,8$, and 11 . The additional doses of supportive therapy increased the complexity, but still, not too bad. But just in case, I set primary and back-up alarms to make sure I especially wouldn't miss the evening medications since I wasn't used to taking medications at that time of day. I also set alarms for the weekend diphenhydramine, and I had a dinner-time alarm to take my vitamin B complex (for prevention of peripheral neuropathy). There were several days I thought how complicated this all must be for a person who is not a healthcare professional, who might not have thought to set alarms, or create a calendar, or thought ahead to call in for medication refills. I was reminded again how important it is to not just educate patients how to take their medications and warn them of possible side effects at the initial visit, but to continue inquiring, educating, and caring with each and every encounter.

Even though I did not have any major adverse reactions, perhaps the adverse effect I was most worried about getting was peripheral neuropathy, but not for the reasons one might expect. While I certainly didn't want the pain or possible irreversibility of peripheral neuropathy, I mostly didn't want this side effect to hinder my ability to hand-sew or crochet. These are two hobbies that I find immensely enjoyable and relaxing; they are major stress reducers for me, and I desperately did not want to have to give these things up. The rational part of me said that was a silly thing to be the most worried about (given the risk of a DVT or pulmonary embolism with lenalidomide), but this experience gave me an entirely new perspective into just how important it is to ask patients specifically what concerns them most about their disease and treatment.

As I thought back to how I did not want to read anything about MM initially, it occurred to me that perhaps this is what patients go through with ANY type of diagnosis, not just a cancer diagnosis. The patient with an elevated hemoglobin A1C receives information concerning steps to take with diet, exercise, medications, and lifestyle changes, and seems to have all the tools at his fingertips to lower that number, yet a threemonth follow-up visit shows no change. Rather than making any of the many assumptions we could as to what led the patient to not implement healthy changes, perhaps we might consider the patient is still in shock over receiving such news and needed time to process the impact such a diagnosis brought into his life. Compassionately helping this patient take baby steps to improve his health may have an immensely positive impact on this patient for years to come.

\section{Insights into people surrounding me}

A difficult diagnosis certainly impacts the person receiving such news, but it goes without saying that it also has a significant impact to all those surrounding the patient. Naturally, my immediate family (husband Rob, and 2 college-age children Melanie and Matthew), have been impacted in a major way. My children are not going on a mission trip this summer, my husband is taking 6 weeks off work, we are not going on a major 
family vacation, and everyone is going to counseling that we likely wouldn't be were it not for me having cancer. I could talk for days about how each person has responded. Each one is unique, and each response is special. Rob has been my chief caregiver, managing the communication flow and filtering information to me as I've been able/willing to process. He's also educated himself as much as possible about MM and its treatments, investigated the financial considerations, and has been responsible for the house and yard upkeep, etc. Melanie has a harder time talking about the fact that I have MM. It doesn't take much for her to become teary when we're talking about it. She has quietly done extra things around the house and bought me little gifts she knows I would like. She will be the one in charge of my medications post-transplant (since I will not be allowed to give myself medications for the first few weeks after hospital discharge). Matthew is more like Rob and tackles issues head-on. He was away at school when we shared the diagnosis with him over the phone and through much of my induction therapy. He asks a lot of questions, even the tough ones. Matthew has appointed himself my personal chef posttransplant.

My extended family (parents, brothers, sister, nephews, niece, in-laws, etc.) are all more than $\mathbf{5 0 0}$ miles away, so in many ways there is less they are able to do. Most send frequent texts or emails to let me know they're thinking of me. A few are having a difficult time dealing with the fact that I have cancer and have minimized their contact with me.

As expected, reactions from friends, acquaintances, and colleagues are varied. At times, people don't say anything for fear of saying 'the wrong thing'. This can lead to feelings of isolation and a sense of abandonment to the person with cancer. In other instances, despite their best intentions, people say things that might not be very helpful. As one cancer survivor explained: "One thing that friends and co-workers did that did NOT help was tell me stories about people with cancer who didn't make it. I didn't really need to hear that and sometimes that can still set me off. Instead of saying, 'Please don't share any more with me, 'or 'I'd prefer not to hear this,' I'd just stand there and listen. That was stupid. In retrospect, I should have just politely cut it off." 4 I think it would be encouraging for people to know that most of the time what people say is not 'wrong'; in fact, it's exactly the support friends and loved ones need to hear in the moment. Family and friends may find it helpful to review online tips ${ }^{5-6}$ prior to talking with their loved one. This information may empower them to reach out rather than remain silent, to listen more and dispense advice less.

I teach and interact with pharmacy and physician assistant students on a daily basis. I have been absolutely blown away by the concern, compassion, support, thoughtfulness, kindness, and love they have shown me over the past several months. I have received several cards, flowers, desserts, and emails from them, along with a 'goodie basket' full of so many of my favorite things! I have truly appreciated those who stop by my office to ask how l'm doing and what's my next step in the process. The day after I received my diagnosis, I inadvertently shared the news with 55 physician assistant students at the end of class. I hadn't intended to say anything just yet, but a question had come up about the summer course and knowing I would be on medical leave at that time, I found myself sharing the news with them. Their compassion was palpable. Immediately after the class was over, I informed the program's assistant director that my news was out. She sent me the following reply: "Despite your misgivings about whether you should have or shouldn't have spoken to them so honestly this day, you have given them a gift. The gift of your story, as raw and new as it is, opens their eyes to the reality of people processing diagnoses, altering life plans, waking up to a new reality. We can talk about in a theoretical sense all day long but I'm sure you touched their hearts and minds in a powerful way today." This physician assistant's response was personal affirmation that it was okay to be open and vulnerable, to share my story. Support groups of all types (cancer, addiction, divorce, etc.) are filled with individuals who share personal stories of loss and despair, hope and triumph. It's why books and movies that are "based on a true story" are advertised as such - people love to read and hear about the struggles and victories that real people experience. Although it's impossible to know the potentially far-reaching effect such stories will have on others, chances are good that at least one person will be positively impacted through the sharing of another person's story.

\section{Insights into myself}

The insights I've learned about myself spill over into all the other categories as well, but there are several specific observations I've learned about myself these past few months. My current circumstances haven't changed the fact that when I was 11 years old, I placed my eternal hope in Jesus Christ. My faith in God has not wavered throughout this process. I have not asked "Why me?" In fact, I've said "Why not me?" I mean, who am I to not be personally affected by cancer? But lest anyone think I'm just a bit too pious for my own good, I freely admit that I have questioned "Why now?" Why at age $52 \mathrm{am}$ I having to deal with a relapsing/refractory cancer? Why at this point in my marriage, my children's lives? Why at this point in my career? I don't have specific answers to those questions, but ultimately I know that God is in control and everything works in His timing, according to His perfect will.

Independent. Self-sufficient. In control. I'm less inclined to use these words to describe myself these days. On the day I shared my diagnosis with a few close colleagues, I received an offer of a home-cooked meal delivered to my house that night. Treatment wasn't going to start for another 2 weeks, and I remember asking my husband whether we should decline for now, waiting instead until things "started" before accepting offers of help. It hit me that even though chemotherapy hadn't officially started, this cancer thing had really started. We said yes to that meal and have graciously accepted additional offers from those who created a meal train on our behalf. It was so 
encouraging to see that meal train quickly fill up with church friends, colleagues, and other people we didn't even know who wished to bless us with a meal.

Upon first hearing of my diagnosis, many people offered to help by accompanying me to my appointments, doing housework and yard work, and running errands for me. I created a list of those various offers but was at a loss as to how to ask for that kind of help. My husband went with me to my first and third treatments - I went by myself to the second treatment. The day before my fourth treatment, a friend texted me to say she wanted to take me to my appointment the following day. There was a part of me that felt it was unnecessary to have someone go with me since I could still drive, and, since I was getting the bortezomib subcutaneously (as opposed to an infusion), I was never at the clinic very long. The fact that she remembered when my treatment was due and didn't ask if I wanted her to go with me but instead said she would love to be with me, touched me deeply. For subsequent cycles of chemotherapy, I reached out to others on my list and asked if they were able to accompany me. I came to realize there was so much to be gained through the comfort of friends who were just there with and for me. The fact that they could understand and visualize the process was not only helpful to me, but it allowed them to be more invested in what I was going through. As several people have said to me, this is not just my journey, it's a journey for everyone around me as well. Because of my friends, husband, and children, that second treatment was the only treatment I went to alone.

I am often asked how I am doing physically, spiritually, mentally, and emotionally. At the outset, I might have thought the physical aspect of cancer would be the most challenging, but because I had no disease-specific symptoms and I've tolerated the chemotherapy very well, I've not been challenged too much in a physical way. Spiritually, I have peace about where I stand in this regard, so this, too, has not been a challenge but rather an area of comfort for me. Mentally, it depends on who you talk to (haha!) as I feel not too much has changed in this area, unless you count the times l've lost my train of thought or had difficulty with word-finding (we're blaming it on 'chemo brain'!). Emotionally - I've been surprised to find myself most challenged with this area. For the most part, I've been fairly even keeled, but I did have a particularly down day and then one roller-coaster ride of a week. My closest support network helped get me through those times. But there are other times, the times I don't tend to share with others, when the tears are on the surface, when the thoughts swirl at night and I can't fall back to sleep, or when I start to think of all the 'what-ifs'- those times are hard. But it's usually during those times I get the 'random' text, email, card, verse, prayer, gift, meal, or blessing of someone's support. Someone in my wonderful support group who sent me a message that came at just the right time. It's not so much the message, although the words, Scripture verse, or song lyrics are often perfect for the situation, but it's the fact that someone cared to reach out and say, "I'm thinking of you." For all those people who have done that for me and do that for others in their lives, I don't think they will ever truly know what an absolute blessing they are!

I started a 'Gratitude Journal' a few months ago. I found this idea in a Coping with Cancer magazine. ${ }^{7}$ Practicing gratitude has many positive physical, mental, emotional, and spiritual benefits. It has also helped me move through the stages of grief to arrive at acceptance in a healthy way. The purpose of my journal is to recognize those many things around me that I can choose to be thankful for. Even though there are several things I am grateful for in a given day, as evidenced by the many scenarios I've already described in this article, I focus on just one thing. Each entry begins with "I'm grateful for..." and is followed by a specific story that tells of a particular person, event, or blessing I received that day. I might write about a family member, the friend who took me to an appointment or brought me a meal, or the fact that another day had gone by without developing a major side effect. I started this journal a few months ago, and not a day has passed that I haven't been able to find at least something for which to be thankful.

Even though others have referred to my chemotherapy treatments and upcoming stem cell rescue, and all of the life changes that go along with this, as a 'journey', it's not really clear to me why we use this word. At times, it seems the phrase 'hot mess' is a more appropriate description of these disruptions to my life! As a noun, the definition of journey is 'an act of traveling from one place to another'. Without sounding too melodramatic, most synonyms for journey such as trek, voyage, adventure, odyssey, outing, and jaunt don't seem to convey the right degree of gravity for my situation. I did find one synonym, though, that might fit my disease course. That word is 'passage'. I have passed through a former phase of life where things were comfortable and routine into a new phase of life where things are uncomfortable and scary. I'm reminded of the song we used to sing to our kids called "We're Going on a Bear Hunt". Some of the lyrics include the phrases, "We can't go over it. We can't go under it. We've got to go through it." I hold onto hope that I will soon pass through my current situation into yet another phase of life, a phase where things might not ever be like they once were, but perhaps can become comfortable and routine once again.

Temporarily standing in the way of my comfort and new routine, however, is the next phase of my treatment course. I will undergo a stem cell rescue (aka stem cell transplant or bone marrow transplant) in just a few weeks. The entire transplant process will bring a whole host of other thoughts and feelings that will likely overshadow what I've experienced to this point, which is why I wanted to take time to capture and reflect on my current feelings while they are still fresh in my mind. I reached the acceptance stage of this cancer diagnosis a few months ago, but some days it still feels surreal that I'm even having these conversations about chemotherapy and stem cell transplants with providers, family, and friends. It has helped me 
tremendously to transform the thoughts in my mind into words on paper. My goal is to do the same with all I experience during this next phase of therapy.

Thank you for allowing me to share my experience with you. I'll see you on the other side of the transplant...

\section{Acknowledgements}

Family: Rob, Melanie, Matthew, Dad \& Mom, Dad \& Mom Smith, Mark, Michele, Brian, Melanie, Jared, Jacob, Colleen, Luke, Rachel.

Friends: Karyn, Raina, Ashley, Judith, Pam, Cindy, Jami, Karen, Linda P, Carrie, Angie, Dawn, Lisa S, Michael, Andy, Becky, Roz, Gail, Renee, Helene, Michelle, Laura, Bonnie, and Maddie.

Conflicts of Interest: None. I declare no conflicts of interest or financial interests that the authors or members of their immediate families have in any product or service discussed in the manuscript, including grants (pending or received), employment, gifts, stock holdings or options, honoraria, consultancies, expert testimony, patents and royalties.

Funding/support: None

\section{References}

1. Rajkumar SV, Dimopoulos MA, Palumbo A, Blade J, Merlini G, Mateos MV, et al. International Myeloma Working Group updated criteria for the diagnosis of multiple myeloma. Lancet Oncol 2014;15(12):e538e548. doi 10.1016/S1470-2045(14)70442-5

2. International Myeloma Foundation. (2019, June 4). Retrieved from https://www.myeloma.org/

3. Multiple Myeloma Research Foundation. (2019, June 4). Retrieved from https://themmrf.org/

4. Stewart SK. Autologous Stem Cell Transplants: A handbook for patients. Highland Park, IL: Blood \& Marrow Transplant Information Network;2014:34.

5. Guidance on how to talk to cancer patients and survivors. Cancer Treatment Centers of America. (2019, May 1). Retrieved from https://www.cancercenter.com/community/forcaregivers/cancer-etiquette

6. Supporting a friend who has cancer. American Society of Clinical Oncology. (2019, May 1). Retrieved from https://www.cancer.net/coping-with-cancer/talkingwith-family-and-friends/supporting-friend-who-hascancer

7. Cousin L. The healing power of gratitude for cancer survivors: 5 practice steps you can take this week to cultivate gratitude in your life. Coping with cancer. March/April 2019;33(2):10. 


\section{Pictures:}

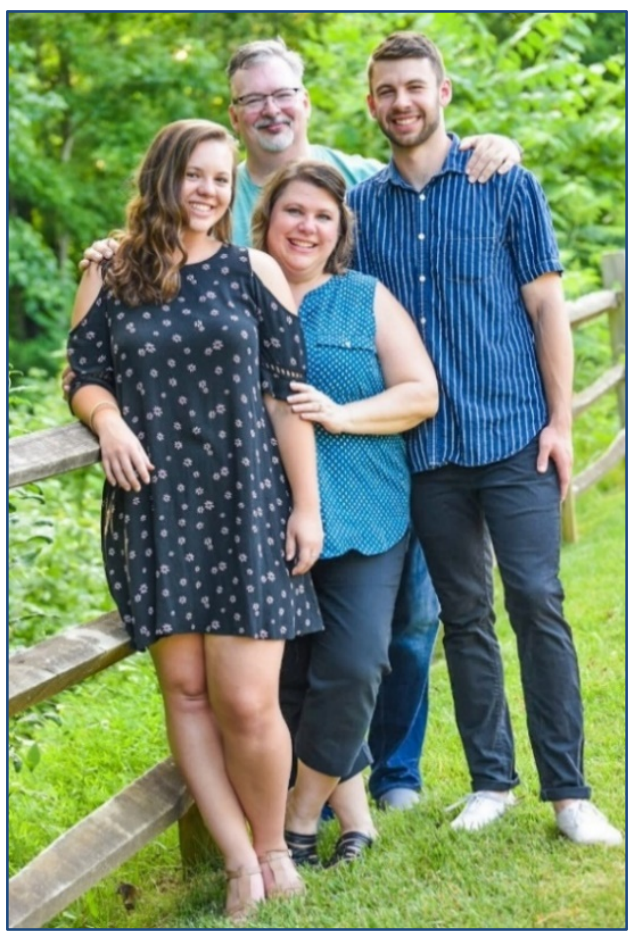

Picture 1. My Family

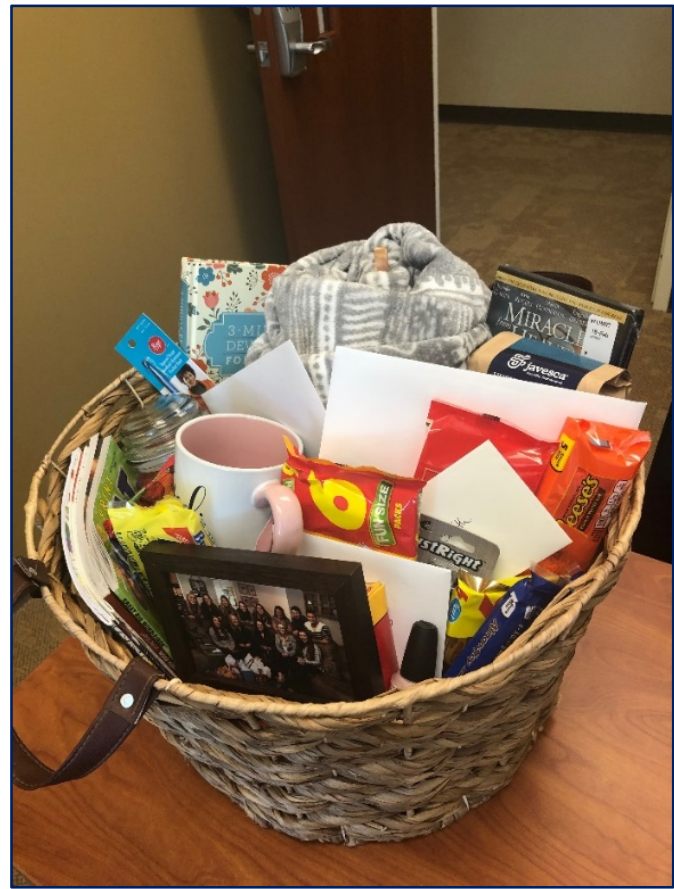

Picture 3. A goodie basket delivered to me by pharmacy students

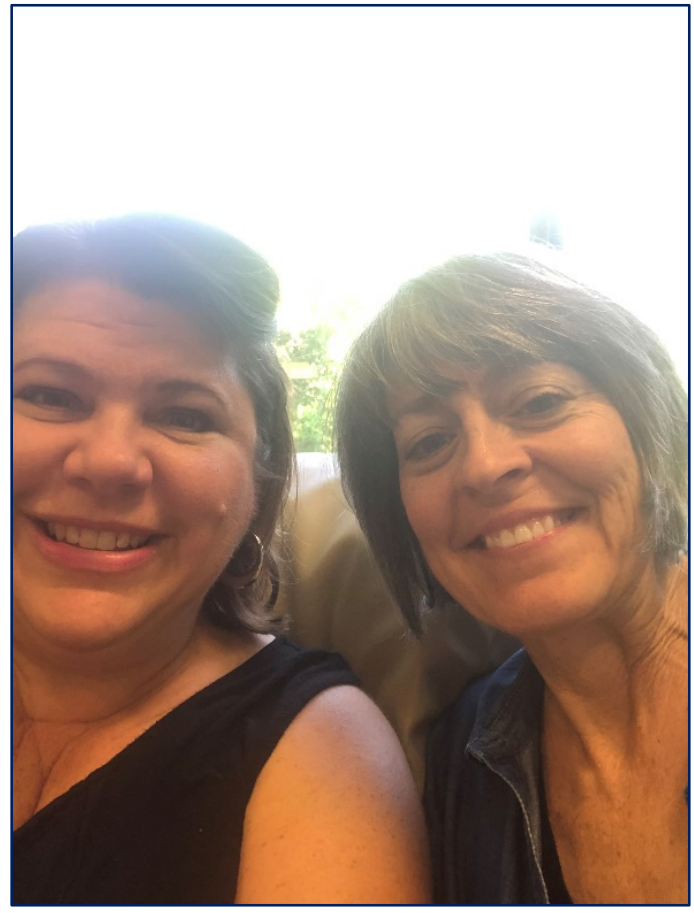

Picture 2. A friend accompanying me to a chemotherapy treatment

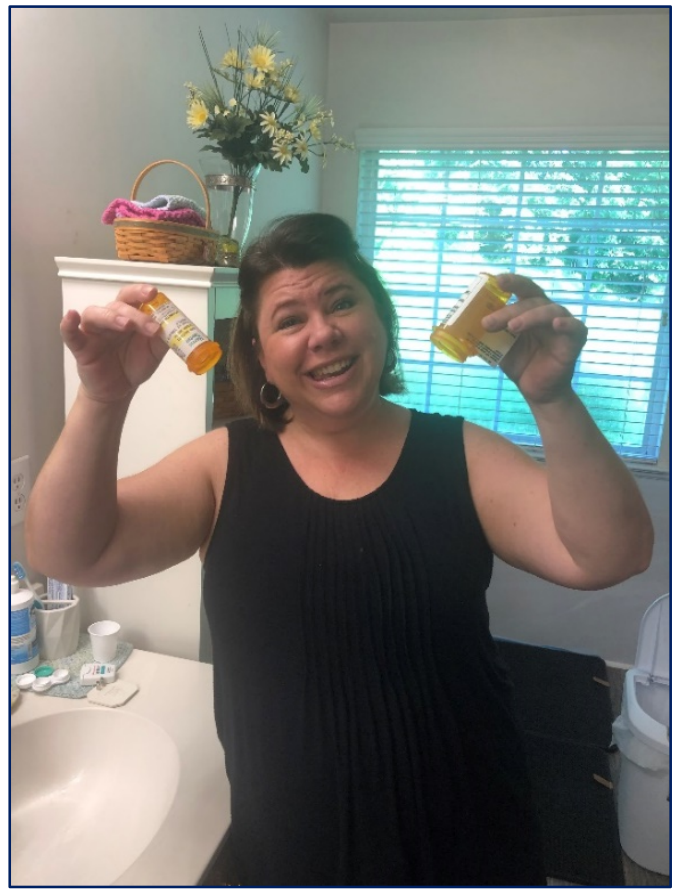

Picture 4. The last day of oral chemotherapy doses 